\title{
Lipodystrophy among HIV-Infected Patients Attending Care and Treatment Clinics in Dar es Salaam
}

\author{
Marina Njelekela, ${ }^{1}$ Rose Mpembeni, ${ }^{2}$ Alfa Muhihi, ${ }^{3}$ Nzovu Ulenga, ${ }^{3}$ \\ Eric Aris, ${ }^{3}$ and Deodatus Kakoko ${ }^{4}$ \\ ${ }^{1}$ Department of Physiology, Muhimbili University of Health and Allied Sciences, P.O. Box 65001, Dar es Salaam, Tanzania \\ ${ }^{2}$ Department of Epidemiology and Biostatistics, Muhimbili University of Health and Allied Sciences, P.O. Box 65001, \\ Dar es Salaam, Tanzania \\ ${ }^{3}$ Management and Development for Health, Mwai Kibaki Road, Mikocheni, P.O. Box 79810, Dar es Salaam, Tanzania \\ ${ }^{4}$ Department of Behavioral Sciences, Muhimbili University of Health and Allied Sciences, P.O. Box 65001, Dar es Salaam, Tanzania
}

Correspondence should be addressed to Marina Njelekela; madaula@yahoo.com

Received 2 June 2017; Accepted 6 September 2017; Published 11 October 2017

Academic Editor: David Katzenstein

Copyright (C) 2017 Marina Njelekela et al. This is an open access article distributed under the Creative Commons Attribution License, which permits unrestricted use, distribution, and reproduction in any medium, provided the original work is properly cited.

\begin{abstract}
Background. HIV infection and long-term HAART use are associated with metabolic and morphological changes. We assessed prevalence, types, and risk factors associated with lipodystrophy among HIV-infected adults attending CTC in Dar es Salaam, Tanzania. Methods. Analysis included $466 \mathrm{HIV}$-infected patients. Study protocol involved administration of structured questionnaire to collect sociodemographic and clinical information. Diagnosis of lipodystrophy was based on physician clinical assessment. Results. Lipodystrophy was present in 95 (20.4\%) of the study participants, with lipoatrophy being the most common (49.5\%) followed by mixed lipodystrophy (37.9\%), and lipohypertrophy was the least prevalent (12.6\%). Male gender, older age, long duration on HAART, and use of Stavudine containing regimen were associated with lipodystrophy (all $p<0.05$ ). The risk for lipodystrophy was 1.6 times $(\mathrm{AOR}=1.66,95 \% \mathrm{CI}=1.01-2.72)$ for male participants and 13.3 times $(\mathrm{AOR}=13.3,95 \% \mathrm{CI}=6.4-27.7)$ for those on HAART. Long duration on HAART and use of Stavudine containing regimen were also associated with increased risk for lipodystrophy. Lipodystrophy was associated with poor perception about own body image and decreased social interactions. Conclusions. Lipodystrophy is common among HIV-infected patients in Tanzania, especially among male patients and those on HAART. Regular screening, monitoring, and patient awareness are needed for early identification and appropriate management.
\end{abstract}

\section{Introduction}

The recent estimates by UNAIDS indicate that 36.7 million [34.0 million-39.8 million] people were living with HIV in 2015 with Sub-Saharan Africa (SSA) bearing an inordinate share $(70 \%)$ of the global HIV burden [1]. The number of HIV-infected people accessing Highly Active Antiretroviral Therapy (HAART) increased from 5.2 million in 2009 to 17.0 million in 2015 [1]. Of the estimated 1.1 million AIDS-related deaths in 2015, nearly three-quarter (73\%) occurred in SSA [1]. In Tanzania, HIV incidence slowed to about 3.4 per 1000 person-years between 2004 and 2008 [2]. Data from the 2012 Tanzania HIV/AIDS and Malaria Indicator Survey (THMIS) indicated the national prevalence of HIV was 5.1\% among the sexually active populations (15-49 years) and was higher among women (6.2\%) compared to $3.8 \%$ in men [3].

The introduction of HAART provided HIV/AIDS patients with opportunity for quality of life improvement by inhibiting disease progression and development of opportunistic infections $[4,5]$. Studies have indicated decreased HIV transmission and AIDS-related morbidity and mortality in both developed and developing countries $[6,7]$ resulting from high coverage of HAART. The provision of HIV services including HAART in Tanzania began in October 2004 with triple therapy consisting of 2 Nucleoside Reverse Transcriptase Inhibitors (NRTIs) + 1 Non-Nucleoside Reverse Transcriptase Inhibitor (NNRTI), 2 NRTIs +1 Protease Inhibitor (PI), or 3 NRTIs being recommended [8]. The current National 
Guidelines for Management of HIV and AIDS provides drug combinations options for first-line treatment according to indications and contraindications. However, the current default first-line regimen in Tanzania is Tenofovir (TDF) $300 \mathrm{mg} /$ Lamivudine (3TC) $300 \mathrm{mg} /$ Efavirenz (EFV) $600 \mathrm{mg}$ once daily at night [9]. Introduction of fixed dose combination therapy has significantly reduced pill burden to HIV patients and improved adherence to treatment $[10,11]$.

HIV infection and HAART have been associated with development of cardiovascular and metabolic complications including lipodystrophy $[12,13]$. These effects are mediated through mitochondrial toxicity [13], atherosclerosis, and increased levels of inflammatory markers such as C-reactive protein, interleukin 6 , cystatin $\mathrm{C}$, and $\mathrm{D}$-dimer all of which are associated with CVD risk [14, 15]. Lipodystrophy syndrome encompasses three clinical conditions characterized by abnormal body fat distribution; (i) lipoatrophy (peripheral fat wasting), (ii) lipohypertrophy (central fat accumulation), and (iii) mixed lipodystrophy (combination of both lipoatrophy and lipohypertrophy). Lipodystrophy patients have characteristic peripheral fat loss in the face, limbs, and buttocks, accompanied by central fat accumulation in the abdomen and breasts and over the dorsocervical spine ("buffalo hump") and lipomas [16]. Protease Inhibitors (PI) containing regimen have been most strongly linked to body fat maldistribution syndrome $[17,18]$. Non-Nucleoside Reverse Transcriptase Inhibitors (NRTIs) especially Stavudine have also been associated with body fat maldistribution [19]. The overall prevalence of at least one physical abnormality related to body fat maldistribution has been estimated at about 50\% after one year of using HAART [20]. Other factors, such as duration of HIV infection, age, and gender, may also contribute to the risk of development of lipodystrophy [21]. Studies have shown that body fat changes are associated with psychological trauma which may be severe enough to affect a patient's desire to continue with HAART, limit therapy options, and profoundly affect the quality of life [22].

As Tanzania scales up HAART to all HIV-infected individuals country-wide through the "test and treat" strategy, it is critical to understand the proportion of HIV-related body fat maldistribution among HIV-infected people on treatment, so as to design and institute interventions that will minimize the risk for lipodystrophy. This study was therefore conducted to determine the prevalence, types, and risk factors associated with lipodystrophy among HIV-infected adults attending Care and Treatment Clinic (CTC) at three municipal referral hospitals in Dar es Salaam, Tanzania.

\section{Materials and Methods}

2.1. Study Design, Site, and Participants. This cross-sectional analytical study was conducted at Amana, Temeke, and Mwananyamala Municipal Hospitals in Dar es Salaam. At the time of data collection, Amana Hospital CTC had 14,133 active clients (with 7,932 on treatment and 6,201 under care and monitoring); Temeke Hospital CTC clinic had 16,530 active clients (with 8,871 on treatment and 7,659 under care and monitoring), and Mwananyamala Hospital CTC had
17,746 active clients (with 9,193 on treatment and 8,553 under care and monitoring).

Dar es Salaam region has a population of more than 4.3 million people, with an HIV prevalence of 5.1\% among sexually active age group [3]. Study participants were HIVpositive patients aged $\geq 18$ years who had been attending CTC at the three aforementioned municipal referral hospitals for at least 24 months.

2.2. Eligibility and Sampling Procedure. Stratified sampling was used to enroll participants into the study. The daily appointment list of patients was obtained from the hospital CTC records one day in advance. From this list the two groups (HAART and HAART naïve) and duration for which the patient has been attending CTC were determined. The list of patients who had attended CTC clinic for $\geq 24$ months formed the sampling frame. Selection of patients from each stratum was done using simple random sampling techniques. Inclusion criteria were men and women aged $\geq 18$ years, had attended CTC for $\geq 24$ months, on HAART or HAART naïve, were clinically stable with good general condition, and provided a signed informed consent to participate. Pregnant women and very sick patients (Karnofsky score $\geq 40 \%$ ) [23] were excluded from the study.

\subsection{Recruitment of Research Assistants and Training. Six} research assistants (3 physicians and 3 nurses) working at the CTC in the three municipal hospitals were recruited to assist during data collection. Selected study physicians and nurses had experience working at the CTC and had good interview and communication skills. Study physicians and nurses received training on the objectives of the study, recruitment, and assessments procedures, as well as importance of ensuring data quality.

2.4. Study Protocol. The study protocol involved administration of a questionnaire and physical examination. Sociodemographic information including age, sex, marital status, level of education, source of income, and lifestyle related information (smoking, alcohol drinking, type of diet in the last 24 hours, and physical activity) was assessed. Dietary assessment was conducted using a $24 \mathrm{~h}$ recall system. Based on a list of common foods, which was provided to them at the time of interview, subjects were also asked about food and/or beverages in the past 24 hours. A quick assessment of level of physical activity was conducted using the same interview guide. Participants were then asked to rank themselves in terms of level of physical activity. Duration and type of HAART medications and for HAART naïve the duration since HIV was diagnosed were ascertained from the patient medical records.

2.5. Anthropometric Measurement. Anthropometric measurements including height, weight, and waist and hip circumference were obtained following standardized procedures. Body Mass Index (BMI) was calculated as weight in kilograms divided by height in meters squared $\left(\mathrm{kg} / \mathrm{m}^{2}\right)$, and categorized as underweight $\left(\mathrm{BMI} \leq 18.5 \mathrm{~kg} / \mathrm{m}^{2}\right)$, normal weight (BMI: 
$18.5-24.9 \mathrm{~kg} / \mathrm{m}^{2}$ ), overweight (BMI: $25.0-29.9 \mathrm{~kg} / \mathrm{m}^{2}$ ), and obese $\left(\mathrm{BMI} \geq 30 \mathrm{~kg} / \mathrm{m}^{2}\right)$. Central obesity was defined as waist circumference $\geq 102$ centimeters in men and $\geq 88$ centimeters in women [24].

2.6. Assessment and Definition of Lipodystrophy Syndrome. In order to characterize self-rated body fat maldistribution, study participants were asked if they had noticed any changes that had alerted them in the following:

(i) Increased fat under the chin

(ii) Increased fat on the back of the neck

(iii) Increased abdominal girth

(iv) Increased chest or breast fat

(v) Loss of fat in the face

(vi) Loss of fat in the arms

(vii) Loss of fat in the buttocks

(viii) Loss of fat in the legs.

Information reported by the patient was validated by the physician after conducting a thorough physical examination. Fat maldistribution was scored as none (score $=0)$, mild $($ score $=1)$, moderate $($ score $=2)$, and severe $($ score $=3)$ and was recorded separately for fat losses and accumulations [25]. Lipodystrophy was categorized as

(i) lipoatrophy: presence of at least one site with moderate or severe fat loss,

(ii) lipohypertrophy: presence of at least one site with moderate or severe fat accumulation, excluding isolated abdominal fat accumulation,

(iii) mixed lipodystrophy: presence of signs of both lipoatrophy and lipohypertrophy.

2.7. Ethical Clearance. Ethical approval to conduct the study was obtained from Research Ethics Committee of the Muhimbili University of Health and Allied Sciences. Permission to conduct the study at the municipal hospitals was obtained from respective municipal medical officers of health through municipal research coordinators, who notified the medical officers in charge of the municipal hospitals. Medical officers in charge are overseers of these hospitals and facilitated to ensure that data collection was conducted smoothly.

The purpose of the study, expected duration of the participant's involvement, and description of the study procedures to be followed were clearly explained to potential participants. Description of any reasonably foreseeable benefits to the participant, such as awareness of body fat maldistribution risk factors and how they are going to be protected, for example, treatment of hypercholesterolemia, proper diet, and adequate physical activity, was done before enrolment. Risks or discomforts such as longer duration of interviews were also communicated in advance. Only those who agreed by signing informed consent were interviewed and were free to withdraw from the study during interview. To ensure confidentiality, participants were assigned unique identification numbers that were used during data collection.
2.8. Data Collection and Management. Data collected was edited during and after collection and adjusted for some missing information. The principal investigator scheduled visits to the study sites to observe and supervise data collection as per interview guide to ensure quality data. The principal investigator was also available for clarifications as another means of quality check. Therefore, the risk of study physicians and nurses recording wrong responses on account of misunderstanding the questions was minimized. Coding for open ended questions was done by the team and thereafter data was entered by the trained data entrant. Data cleaning and analysis were done using SPSS version 20.0 for windows.

2.9. Data Analysis. Frequency distribution was done to all variables to assess their distribution in the study population. Two-way tables were used to assess the association between dependent and independent variables by using the $\chi^{2}$-test. Multiple logistic regressions were used to assess individual contribution of each independent variable in predicting body fat maldistribution while controlling for confounding variables. In all the analyses, the $p$ values were 2 -sided and $p \leq 0.05$ was considered statistically significant.

\section{Results}

3.1. Sociodemographic and General Characteristics of Study Sample. A total of $466 \mathrm{HIV}$-infected patients attending CTC at Amana, Temeke, and Mwananyamala Municipal Hospitals were included in the analysis. Demographic and general characteristics of the study participants are summarized in Table 1. Three-quarter (74.9\%) of the participants were females. The mean age of the study participants was $41.1 \pm 9.8$ years, with majority (41.6\%) being in the age group of 31-50 years. Nearly half $(47.0 \%)$ of the participants were married or cohabiting, and majority had primary level of education (76.4\%). Half of the participants $(51.1 \%)$ were on HAART, with $49.6 \%$ of them being on Efavirenz based regimen, $36.1 \%$ on Stavudine based regimen, $13.0 \%$ on Nevirapine based regimen, and only $1.3 \%$ on Protease Inhibitor based secondline regimen. Majority (62.6\%) of HAART patients were on treatment for 24-48 months.

3.2. Prevalence of Lipodystrophy. Prevalence of lipodystrophy was $20.4 \%$ with primary lipoatrophy $(49.5 \%)$ being the most prevalent form of lipodystrophy followed by mixed lipodystrophy (37.9\%) and primary lipohypertrophy (12.6\%) was the least common (Table 1). A similar trend was observed for self-rating where $114(24.5 \%)$ reported to have noted changes in body fat maldistribution, with more participants reporting decreased size of their body parts (17.5\%) compared to increased size of body parts (14.0\%).

3.3. Factors Associated with Lipodystrophy. Table 2 presents the characteristics of HIV-infected patients with lipodystrophy. Male participants were affected more than female participants (26.5\% versus $18.3 \%$; $p=0.058$ ). However, the overall prevalence of overweight and that of obesity was significantly higher among women compared to men $(25.8 \%$ 
TABLE 1: Sociodemographic and general characteristics of the study participants.

\begin{tabular}{|c|c|}
\hline Characteristic & Number (\%) \\
\hline \multicolumn{2}{|l|}{ Age (years) } \\
\hline$\leq 30$ years & $51(10.9)$ \\
\hline $31-40$ years & $194(41.6)$ \\
\hline $41-50$ years & $134(28.8)$ \\
\hline$\geq 51$ years & $67(14.4)$ \\
\hline Missing & $20(4.3)$ \\
\hline \multicolumn{2}{|l|}{ Gender } \\
\hline Male & $117(25.1)$ \\
\hline Female & $349(74.9)$ \\
\hline \multicolumn{2}{|l|}{ Marital status } \\
\hline Married & $219(47.0)$ \\
\hline Single & $89(19.1)$ \\
\hline Divorced/separated & $81(17.4)$ \\
\hline Widowed & $77(16.5)$ \\
\hline \multicolumn{2}{|l|}{ Education level } \\
\hline No formal education & $27(5.8)$ \\
\hline Primary education & $356(76.4)$ \\
\hline Secondary education & $68(14.6)$ \\
\hline College/university & $15(3.2)$ \\
\hline \multicolumn{2}{|l|}{ CTC of enrolment } \\
\hline Amana Hospital & $152(32.6)$ \\
\hline Temeke Hospital & $155(33.3)$ \\
\hline Mwananyamala Hospital & $159(34.1)$ \\
\hline \multicolumn{2}{|l|}{ HAART use } \\
\hline On HAART & $238(51.1)$ \\
\hline HAART naïve & $228(48.9)$ \\
\hline \multicolumn{2}{|l|}{ Type of HAART } \\
\hline Nevirapine based regimen & $31(13.0)$ \\
\hline Efavirenz based regimen & $118(49.6)$ \\
\hline Stavudine based regimen & $86(36.1)$ \\
\hline Protease Inhibitor based regimen & $3(1.3)$ \\
\hline \multicolumn{2}{|l|}{ Duration of HAART use } \\
\hline HAART naïve & $228(48.9)$ \\
\hline 24 months & $60(12.9)$ \\
\hline 25-48 months & $149(32.0)$ \\
\hline$>48$ months & $29(6.2)$ \\
\hline \multicolumn{2}{|l|}{ Lipodystrophy } \\
\hline Yes & $95(20.4)$ \\
\hline No & $371(79.6)$ \\
\hline \multicolumn{2}{|l|}{ Types of lipodystrophy } \\
\hline Primary lipoatrophy & $47(49.5)$ \\
\hline Primary lipohypertrophy & $12(12.6)$ \\
\hline Mixed lipodystrophy & $36(37.9)$ \\
\hline \multicolumn{2}{|l|}{ Body Mass Index (BMI) } \\
\hline Underweight & $58(12.5)$ \\
\hline Normal weight & $235(50.5)$ \\
\hline Overweight & $110(23.7)$ \\
\hline Obese & $62(13.3)$ \\
\hline \multicolumn{2}{|l|}{ Central obesity } \\
\hline No & $301(64.7)$ \\
\hline Yes & $164(35.7)$ \\
\hline
\end{tabular}

BMI: Body Mass Index; CTC: Care and Treatment Clinic; HAART: Highly Active Antiretroviral Therapy.

versus $17.2 \%$ ) for overweight and (16.3\% versus $4.3 \%$ ) for obesity (results not shown). Participants in the age group
41-50 years had the highest proportion of participants with lipodystrophy $(27.6 \%)$ followed by those aged $>50$ years $(25.4 \%)$ and low proportion for younger participants $(p=$ $0.003)$.

As for HAART status, lipodystrophy was higher $(36.1 \%$ versus $3.9 \%$ ) among participants on HAART compared to HAART naïve participants $(p<0.001)$. Differences in prevalence of lipodystrophy were also observed with the type of HAART used. Prevalence of lipodystrophy was highest for participants receiving second-line PI based regimen (66.7\%) followed by Stavudine based regimen (53.5\%). Nevirapine and Efavirenz based regimens had relatively similar rates of lipodystrophy $(25.8 \%$ and $25.4 \%$, resp.). The differences in the prevalence of lipodystrophy by type of HAART were statistically significant $(p<0.001)$. Duration of HAART use showed a U-shaped relationship with lipodystrophy. Patients on HAART for $>48$ months had highest proportion of lipodystrophy followed by those on HAART for 24 months and low in patients on HAART for $25-48$ months $(p<0.001)$

Lipodystrophy was highest among underweight patients (27.6\%) followed by normal weight patients $(21.7 \%)$ and least among obese patients (8.1\%). The difference was statistically significant $(p=0.048)$. Although it did not attain statistical significance, prevalence of lipodystrophy was slightly higher among patients with central obesity $(22.0 \%)$ compared to those without central obesity $(19.6 \%)$.

3.4. Factors Associated with Different Types of Lipodystrophy. Table 3 presents analysis of factors associated with different types of lipodystrophy. Prevalence of primary lipoatrophy was significantly higher for patients aged more than 40 years $(p=0.004)$, male gender $(p=0.004)$, HAART use, longer duration of $>48$ months, and Stavudine based regimen (all $p<0.01$ ). As for primary lipohypertrophy, significant association was observed with only duration of HAART use $(p=0.025)$ and was highest for patients on HAART for 24 months. Mixed type lipodystrophy was found to be associated with education level ( $p=0.039)$, HAART use $(p<0.001)$, Protease Inhibitor based regimen $(p=0.013)$, and using HAART for 24-48 months.

3.5. Determinants of Lipodystrophy. Table 4 shows the results of multiple logistic regressions to determine the most important contributors to lipodystrophy in this population. A model for this analysis contained covariates that attained a statistically significant difference of $p<0.05$ during bivariate analysis. These included age, gender, duration, and types of HAART used. While being in the age group of 31-40 years showed a protective effect $(\mathrm{AOR}=0.18,95 \% \mathrm{CI}=$ 0.05-0.65), older age > 50 years showed a nonsignificant $12 \%$ increased risk for lipodystrophy $(\mathrm{AOR}=1.12,95 \% \mathrm{CI}$ $0.58-2.19)$. Male gender was associated with $66 \%(\mathrm{AOR}=$ $1.66,95 \%$ CI $=1.01-2.72$ ) increased risk for lipodystrophy compared to female gender. Using HAART was associated with 13 times increased risk for lipodystrophy. Similarly, long duration of Stavudine based regimen was significantly associated with 3 times increased risk for lipodystrophy (AOR $=3.22$, $95 \% \mathrm{CI}=1.17-8.81$ ). 
TABLE 2: Factors associated with lipodystrophy among HIV-infected patients in Dar es Salaam.

\begin{tabular}{|c|c|c|c|}
\hline \multirow{2}{*}{ Characteristic } & \multicolumn{2}{|c|}{ Lipodystrophy } & \multirow{2}{*}{$p$ value } \\
\hline & Present & Absent & \\
\hline \multicolumn{4}{|l|}{ Age (years) } \\
\hline$\leq 30$ & $3(5.9)$ & $48(94.1)$ & \multirow{5}{*}{0.003} \\
\hline $31-40$ & $32(16.5)$ & $162(83.5)$ & \\
\hline $41-50$ & $37(27.6)$ & $97(72.4)$ & \\
\hline$>50$ & $17(25.4)$ & $50(74.6)$ & \\
\hline Missing & $6(30.0)$ & $14(70.0)$ & \\
\hline \multicolumn{4}{|l|}{ Gender } \\
\hline Male & $31(26.5)$ & $86(73.5)$ & \multirow{2}{*}{0.058} \\
\hline Female & $64(18.3)$ & $285(81.7)$ & \\
\hline \multicolumn{4}{|l|}{ Marital status } \\
\hline Married & $41(18.7)$ & $178(81.3)$ & \multirow{4}{*}{0.860} \\
\hline Single & $20(22.5)$ & $69(77.5)$ & \\
\hline Divorced/separated & $17(21.0)$ & $64(79.0)$ & \\
\hline Widowed & $17(22.1)$ & $60(77.9)$ & \\
\hline \multicolumn{4}{|l|}{ Education level } \\
\hline No formal education & $6(22.2)$ & $21(77.8)$ & \multirow{4}{*}{0.484} \\
\hline Primary education & $68(19.1)$ & $288(80.9)$ & \\
\hline Secondary education & $16(23.5)$ & $52(76.5)$ & \\
\hline College/university & $5(33.3)$ & $10(66.7)$ & \\
\hline \multicolumn{4}{|l|}{ HAAT use } \\
\hline On HAART & $86(36.1)$ & $152(63.9)$ & \multirow{2}{*}{$<0.001$} \\
\hline HAART naïve & $9(3.9)$ & $219(96.1)$ & \\
\hline \multicolumn{4}{|l|}{ Type of HAART } \\
\hline Nevirapine based regimen & $8(25.8)$ & $23(74.2)$ & \multirow{4}{*}{$<0.001$} \\
\hline Efavirenz based regimen & $30(25.4)$ & $88(74.6)$ & \\
\hline Stavudine based regimen & $46(53.5)$ & $40(46.5)$ & \\
\hline Protease Inhibitor based regimen & $2(66.7)$ & $1(33.3)$ & \\
\hline \multicolumn{4}{|l|}{ Duration of HAART use } \\
\hline HAART naïve & $9(3.9)$ & $219(96.1)$ & \multirow{4}{*}{$<0.001$} \\
\hline 24 months & $23(38.3)$ & $37(61.7)$ & \\
\hline 24-48 months & $51(34.2)$ & $98(65.8)$ & \\
\hline$>48$ months & $12(41.4)$ & $17(58.6)$ & \\
\hline \multicolumn{4}{|l|}{ Body Mass Index (BMI) } \\
\hline Underweight & $16(27.6)$ & $42(72.4)$ & \multirow{4}{*}{0.048} \\
\hline Normal weight & $51(21.7)$ & $184(78.3)$ & \\
\hline Overweight & $23(20.9)$ & $87(79.1)$ & \\
\hline Obese & $5(8.1)$ & 57 (91.9) & \\
\hline \multicolumn{4}{|l|}{ Central obesity } \\
\hline No & $59(19.6)$ & $242(80.4)$ & \multirow{2}{*}{0.630} \\
\hline Yes & $36(22.0)$ & $128(78.0)$ & \\
\hline
\end{tabular}

BMI: Body Mass Index; HAART: Highly Active Antiretroviral Therapy.

3.6. Perceptions Related to Body Image and Quality of Life. Participants' perceptions about their body image and social life are summarized in Table 5 . About $15.8 \%$ of the participants felt strongly that their current body outlook/image was worse compared to the way they looked before and
$10.5 \%$ reported to dislike their mirror images. On average $24.5 \%$ of the participants with lipodystrophy avoided wearing clothing that display their body and $7.4 \%$ did so much more often. As for social aspects of life, $11.6 \%$ of the participants worried much about going into gatherings. Others reported 
TABLE 3: Factors associated with different types of lipodystrophy among HIV-infected patients in Dar es Salaam.

\begin{tabular}{|c|c|c|c|c|c|c|c|c|c|}
\hline \multirow{2}{*}{ Characteristic } & \multicolumn{3}{|c|}{ Lipoatrophy } & \multicolumn{3}{|c|}{ Lipohypertrophy } & \multicolumn{3}{|c|}{ Mixed lipodystrophy } \\
\hline & Yes & No & $p$ value & Yes & No & $p$ value & Yes & No & $p$ value \\
\hline \multicolumn{10}{|l|}{ Age categories (yrs) } \\
\hline$\leq 30$ & $0(0.0)$ & $51(100.0)$ & \multirow{5}{*}{0.004} & $1(2.0)$ & $50(98.0)$ & \multirow{5}{*}{0.463} & $2(3.9)$ & $49(96.1)$ & \multirow{5}{*}{0.436} \\
\hline $31-40$ & $13(6.7)$ & $181(93.3)$ & & $6(3.1)$ & $188(96.9)$ & & $13(6.7)$ & $181(93.3)$ & \\
\hline $41-50$ & $18(13.4)$ & $116(86.6)$ & & $5(3.9)$ & $129(96.3)$ & & $14(10.4)$ & $120(89.6)$ & \\
\hline$\geq 51$ & $11(16.4)$ & $56(83.6)$ & & $0(0.0)$ & $67(100.0)$ & & $6(9.0)$ & $61(91.0)$ & \\
\hline Missing & $5(33.3)$ & $15(66.7)$ & & $0(0.0)$ & $20(100.0)$ & & $2(9.5)$ & $19(90.5)$ & \\
\hline \multicolumn{10}{|l|}{ Gender } \\
\hline Male & $20(17.1)$ & $97(82.9)$ & \multirow{2}{*}{0.004} & $3(2.6)$ & $114(97.4)$ & \multirow{2}{*}{1.000} & $8(6.8)$ & $109(93.2)$ & \multirow{2}{*}{0.699} \\
\hline Female & $27(7.7)$ & $322(92.3)$ & & $9(2.6)$ & $340(97.4)$ & & $28(8.0)$ & $321(92.0)$ & \\
\hline \multicolumn{10}{|l|}{ Education level } \\
\hline No formal education & $3(11.1)$ & $24(88.9)$ & \multirow{4}{*}{0.797} & $1(3.7)$ & $26(96.3)$ & \multirow{4}{*}{0.204} & $2(7.4)$ & $25(92.6)$ & \multirow{4}{*}{0.039} \\
\hline Primary education & $34(9.6)$ & $322(90.4)$ & & $7(2.0)$ & $349(98.0)$ & & $27(7.6)$ & $329(92.4)$ & \\
\hline Secondary education & $9(13.2)$ & $59(86.8)$ & & $4(5.9)$ & $64(94.1)$ & & $3(4.4)$ & $65(95.6)$ & \\
\hline College/university & $1(6.7)$ & $14(93.3)$ & & $0(0.0)$ & $15(100.0)$ & & $4(26.7)$ & $11(73.3)$ & \\
\hline \multicolumn{10}{|l|}{ HAART use } \\
\hline On HAART & $42(17.6)$ & $196(82.4)$ & \multirow{2}{*}{$<0.001$} & $9(3.8)$ & $229(96.2)$ & \multirow{2}{*}{0.142} & $35(14.7)$ & $203(85.3)$ & \multirow{2}{*}{$<0.001$} \\
\hline HAART naïve & $5(2.2)$ & $223(97.8)$ & & $3(1.3)$ & $225(98.7)$ & & $1(0.4)$ & $227(99.6)$ & \\
\hline \multicolumn{10}{|l|}{ Type of HAART used } \\
\hline Nevirapine based & $1(3.2)$ & $30(96.8)$ & \multirow{4}{*}{0.002} & $2(6.5)$ & $29(93.5)$ & \multirow{4}{*}{0.817} & $5(16.1)$ & $26(83.9)$ & \multirow{4}{*}{0.013} \\
\hline Efavirenz based & $15(12.7)$ & $103(87.3)$ & & $4(3.4)$ & $114(96.6)$ & & $11(9.3)$ & $107(90.7)$ & \\
\hline Stavudine based & $26(30.2)$ & $60(69.8)$ & & $3(3.5)$ & $83(96.5)$ & & $17(19.8)$ & $69(80.2)$ & \\
\hline Protease Inhibitor based & $0(0.0)$ & $3(100.0)$ & & $0(0.0)$ & $3(100.0)$ & & $2(66.7)$ & $1(33.3)$ & \\
\hline \multicolumn{10}{|l|}{ Duration of HAART use } \\
\hline HAART naïve & $5(2.2)$ & $223(97.8)$ & \multirow{4}{*}{$<0.001$} & $3(1.3)$ & $225(98.7)$ & \multirow{4}{*}{0.025} & $1(0.4)$ & $227(99.6)$ & \multirow{4}{*}{$<0.001$} \\
\hline 24 months & $11(18.3)$ & 49 (81.7) & & $5(8.3)$ & 55 (91.7) & & 7 (11.7) & $53(88.3)$ & \\
\hline $24-48$ months & $22(14.8)$ & $127(85.2)$ & & $3(2.0)$ & $146(98.0)$ & & $26(17.4)$ & $123(82.6)$ & \\
\hline$>48$ months & $9(31.0)$ & $20(69.0)$ & & $1(3.4)$ & $28(96.6)$ & & $2(6.9)$ & 27 (93.1) & \\
\hline
\end{tabular}

HAART: Highly Active Antiretroviral Therapy.

on average lack of desire for sexual intercourse (9.7\%), being afraid to be introduced to new people (13.7\%), and avoiding outdoor activities like swimming (16.0\%).

\section{Discussion}

This study aimed at determining the prevalence and factors associated with lipodystrophy, and assessing the perceptions towards body fat maldistribution among HIV-infected individuals attending CTC at three municipal hospitals in Dar es Salaam. Since the advent of HAART globally in 1996, HIVrelated morbidity and mortality have decreased significantly. Now patients are living longer but chronic health complications such as cardiovascular diseases and lipodystrophy represent important health issues in this patient population.

In this analysis, the prevalence of physician diagnosed lipodystrophy was $20.4 \%$. The combined prevalence of overweight and obesity was $37.0 \%$, whereas that of central obesity was $35.7 \%$. The precise definition and estimation of lipodystrophy are important for comparison across studies and populations. Prevalence observed in this study was low compared to findings from studies conducted in Western populations $[26,27]$. Conversely, it was considerably higher than $6.6 \%$ reported among African patients after 18 months of HAART [28]. Two other studies conducted in Africa demonstrated higher prevalence rates of lipodystrophy compared to our study $[29,30]$. The observed low prevalence of lipodystrophy in comparison to objective measures (BMI and waist circumference) and that of other studies conducted in Africa may be caused by clinical diagnosis by the attending physician which is subjective and compounded by malnutrition seen in HIVpositive.

Our study has demonstrated an association between lipodystrophy and demographic characteristics including age, gender, and level of education. In our study the prevalence of lipodystrophy was higher in men than women. Conversely, the prevalence of overweight and obesity as defined by BMI was higher in women compared to men. As for age, lipodystrophy was found to be higher for participants aged 41 years and above. Findings from Rwandan study indicated that age and gender were significantly associated with lipodystrophy [29]. Several other studies have also found a similar association $[31,32]$. In African settings, more women 
TABLE 4: Determinants of lipodystrophy among HIV-infected patients in Dar es Salaam.

\begin{tabular}{|c|c|c|c|}
\hline Variables & $\mathrm{AOR}$ & $95 \% \mathrm{CI}$ & $p$ value \\
\hline \multicolumn{4}{|l|}{ Age (years) } \\
\hline$\leq 30$ & Ref & & \\
\hline $31-40$ & 0.18 & $0.05-0.65$ & 0.009 \\
\hline $41-50$ & 0.59 & $0.30-1.15$ & 0.120 \\
\hline$\geq 51$ & 1.12 & $0.58-2.19$ & 0.735 \\
\hline \multicolumn{4}{|l|}{ Gender } \\
\hline Female & Ref & & \\
\hline Male & 1.66 & $1.01-2.72$ & 0.045 \\
\hline \multicolumn{4}{|l|}{ HAAT use } \\
\hline HAART naïve & Ref & & \\
\hline On HAART & 13.3 & $6.4-27.7$ & $<0.001$ \\
\hline \multicolumn{4}{|l|}{ Type of HAART used } \\
\hline Nevirapine based & Ref & & \\
\hline Efavirenz based & 0.98 & $0.36-2.66$ & 0.962 \\
\hline Stavudine based & 3.22 & $1.17-8.81$ & 0.023 \\
\hline Protease Inhibitor based & 1.06 & $0.08-9.02$ & 1.00 \\
\hline \multicolumn{4}{|l|}{ Duration of HAART use } \\
\hline HAART naïve & Ref & & \\
\hline 24 months & 12.8 & $6.0-27.6$ & $<0.001$ \\
\hline $25-48$ months & 13.6 & $5.7-32.4$ & $<0.001$ \\
\hline$>48$ months & 15.3 & $5.3-43.8$ & $<0.001$ \\
\hline
\end{tabular}

AOR: Adjusted Odds Ratio; CI: Confidence Interval; HAART: Highly Active Antiretroviral Therapy.

than men are generally obese [33] and obesity tends to increase with age and level of education [34].

Type, duration, and current use of HAART especially PI and NNRTI containing regimen are strongly associated with development of severe lipoatrophy [35]. In our study, lipodystrophy was highest for patients on PI based second-line HAART regimen, followed by patients on Stavudine based regimen and Nevirapine based regimen, and least among patients on Efavirenz based regimen. Prospective studies investigating body composition in patients starting HAART for the first time $[35,36]$ have demonstrated initial increases in limb fat during the first few months of therapy, followed by progressive decline during ensuing three years. In one study the decline was estimated to be $14 \%$ per year among white men receiving regimens containing Stavudine or Zidovudine with Lamivudine and either a Protease Inhibitor or NonNucleoside Reverse Transcriptase Inhibitor [36].

Our findings on association of Stavudine and Efavirenz with lipodystrophy are consistent with other studies that used Stavudine and Efavirenz based therapy [29, 37]. NonNucleoside Reverse Transcriptase Inhibitors (NNRTIs), such as Efavirenz, have been associated with in vitro altered deposition of triglycerides in the adipocyte; however its clear clinical implications is still being studied. Thymidine analog Nucleoside Reverse Transcriptase Inhibitors (tNRTIs) are risk factors for mitochondrial dysfunction associated with both dyslipidemia and lipoatrophy (particularly in subcutaneous adipocytes) [37]. Changing patients from thymidine analogs to NRTIs has demonstrated beneficial effects on lipoatrophy [38]. Stavudine, the nucleoside analog with the highest propensity for causing mitochondrial dysfunction, is relatively inexpensive and widely available in the developing world. Zidovudine is also relatively available and has many therapeutic advantages but also carries risk of producing mitochondrial toxicity. Hence the use of these drugs in the developing world will lead to mitochondrial toxicity and development of lipodystrophy as is shown in this study.

This study found diverse emotional feelings among participants regarding perception about their body image and quality of life, ranging from feeling worse than before and feeling bad about own mirror image to avoiding wearing some dressing because of fear of stigma. However, we did not explore the desire to stop treatment because of the change in body image. Other studies have also explored the psychosocial effects of lipodystrophy among HIV patients on HAART $[39,40]$. Lipodystrophy might have substantial psychological repercussions with subsequent negative impact on the patient's quality of life, emergence of depressive symptoms, or anxiety [41, 42]. Moreover, body change status and subsequent stigmatization could produce social isolation and distress and, even, change in beliefs about drugs and consequently decreased adherence to HAART.

As with regard to social life, participants with lipodystrophy reported isolating themselves from other people, tending to avoid outside activities like swimming, avoiding events that will have many people, and a diminished desire for sexual intercourse. Other studies have also demonstrated altered quality of life among patients with lipodystrophy [43]. Bodyshape changes may affect patients' psychosocial function and quality of life and may lead to patients considering cessation 
TABLE 5: Changes in body parts and perceptions about current body image among HIV infected patients in Dar es Salaam.

\begin{tabular}{|c|c|c|c|c|}
\hline \multirow{2}{*}{ Change and perception } & \multicolumn{4}{|c|}{ Extent of perceived change } \\
\hline & None & Very little & Average & Very much \\
\hline \multicolumn{5}{|l|}{ Increased body parts } \\
\hline Neck and chin & $88(93.6)$ & $2(2.1)$ & $4(4.3)$ & $0(0.0)$ \\
\hline Back of shoulders & $83(89.2)$ & $2(2.2)$ & $8(8.6)$ & $0(0.0)$ \\
\hline Breast and/or chest & $71(76.3)$ & $7(7.5)$ & $14(15.1)$ & $1(1.1)$ \\
\hline Abdomen & $66(69.5)$ & $7(7.4)$ & $21(22.1)$ & $1(1.1)$ \\
\hline Waist & $78(85.7)$ & $2(2.2)$ & $10(11.0)$ & $1(1.1)$ \\
\hline \multicolumn{5}{|l|}{ Decreased body parts } \\
\hline Face & $53(57.0)$ & $9(9.7)$ & $25(26.9)$ & $6(6.5)$ \\
\hline Upper limbs & $49(53.8)$ & $15(16.5)$ & $19(20.9)$ & $8(8.8)$ \\
\hline Lower limbs & $49(53.3)$ & $18(19.6)$ & $17(18.5)$ & $8(8.7)$ \\
\hline Buttocks & $54(57.4)$ & $9(9.6)$ & $24(25.5)$ & $7(7.4)$ \\
\hline \multicolumn{5}{|l|}{ Perception about body image } \\
\hline Angry about own body & $60(63.8)$ & $12(12.8)$ & $18(19.1)$ & $4(4.3)$ \\
\hline Avoiding some clothing & $50(53.2)$ & $14(14.9)$ & $23(24.5)$ & $7(7.4)$ \\
\hline Ashamed of own body & $63(66.3)$ & $9(9.5)$ & $19(20.0)$ & $4(4.2)$ \\
\hline Unhappy about mirror image & $49(51.6)$ & $16(16.8)$ & $20(21.1)$ & $10(10.5)$ \\
\hline Conscious of other people & $69(75.8)$ & $16(17.6)$ & $5(5.5)$ & $1(1.1)$ \\
\hline Bad body shape than before & $50(52.6)$ & $10(10.5)$ & $20(21.1)$ & $15(15.8)$ \\
\hline Afraid to mix with other people & $76(80.0)$ & $11(11.6)$ & $8(8.4)$ & $0(0.0)$ \\
\hline \multicolumn{5}{|l|}{ Perceptions related to social life } \\
\hline Avoiding outdoor activities & $67(71.3)$ & $10(10.6)$ & $15(16.0)$ & $2(2.1)$ \\
\hline Avoiding social events with many people & $76(78.4)$ & $7(7.2)$ & $12(12.4)$ & $2(2.1)$ \\
\hline Lack of desire for sexual intercourse & $73(78.5)$ & $8(8.6)$ & $9(9.7)$ & $3(3.2)$ \\
\hline Afraid to be introduced to new people & $73(76.8)$ & $9(9.5)$ & $13(13.7)$ & $0(0.0)$ \\
\hline Afraid to enter a room with new people & $79(83.2)$ & $7(7.4)$ & $9(9.5)$ & $0(0.0)$ \\
\hline Habit to exclude himself from other people & $82(88.2)$ & $6(6.5)$ & $4(4.3)$ & $1(1.1)$ \\
\hline Avoid going into social gatherings/parties & $61(64.2)$ & $7(7.4)$ & $16(16.8)$ & $11(11.6)$ \\
\hline
\end{tabular}

of treatment [44]. However, few studies to date have formally addressed the impact of these changes on the patient. Hence this study demonstrates that there are significant variations in perceptions about body changes and the quality of life of these patients that need to be addressed in a larger and welldesigned study for that purpose.

There are few limitations to our analysis. The crosssectional design does not provide causal association of studies parameters with lipodystrophy. The study included patients who were attending CTC clinics and may not be representative of all HIV-infected individuals. However, the fact that the study was conducted in Dar es Salaam which is metropolitan with a diverse population from nearly all other regions makes it possible for the findings to be generalizable to the broader Tanzanian population. We did not collect detailed information on patient's treatment history. For participants who changed treatment due to side effects, the observed association of HAART regimen and lipodystrophy could have been caused by the previous regimen. Therefore we may have missed the true association of HAART with lipodystrophy. The detailed treatment history could also provide some insights on the quality of care in terms of management for lipodystrophy through change of regimen implicated in causing lipodystrophy. Assessments of body fat changes were done clinically, instead of using specialized instruments such as dual energy X-ray absorptiometry (DEXA) or linear calipers. Nevertheless, subjective assessment is strongly correlated with DEXA [45].

In conclusion, prevalence of lipodystrophy among HIVinfected patients is high and is worsened by HAART use. Our findings clearly demonstrate the long-term side effects of HAART, particularly Stavudine based regimen among HIV-infected patients in Tanzania. Treatment modalities among patients with lipodystrophy was not a scope of this study; however if these patients were adequately treated their perceptions against lipodystrophy could improve their quality of life. Deliberately sought efforts are needed to incorporate management of lipodystrophy and other long-term 
complications of HAART in Tanzania in the era of test and treat for improved adherence and overall improved patient care.

\section{Conflicts of Interest}

The authors declare that there are no conflicts of interest regarding publication of this article.

\section{Acknowledgments}

The authors acknowledge the contribution of the staff of the CTC of the municipal hospitals and patients who participated in the study.

\section{References}

[1] UNAIDS, "Fact sheet," 2016, http://www.unaids.org/sites/ default/files/media_asset/20150901_FactSheet_2015_en.pdf.

[2] T. B. Hallett, J. Stover, V. Mishra, P. D. Ghys, S. Gregson, and T. Boerma, "Estimates of HIV incidence from household-based prevalence surveys," AIDS, vol. 24, no. 1, pp. 147-152, 2010.

[3] TACAIDS, Ministry of Health and Social Welfare: Tanzania HIV/AIDS and Malaria Indicator Survey, 2011/2012, TACAIDS, Dar es Salaam, Tanzania, 2012.

[4] G. Greub, B. Ledergerber, M. Battegay et al., "Clinical progression, survival, and immune recovery during antiretroviral therapy in patients with HIV-1 and hepatitis $\mathrm{C}$ virus coinfection: the swiss HIV cohort study," The Lancet, vol. 356, no. 9244, pp. 1800-1805, 2000.

[5] H. Streeck, H. Jessen, G. Alter et al., "Immunological and virological impact of highly active antiretroviral therapy initiated during acute HIV-1 infection," Journal of Infectious Diseases, vol. 194, no. 6, pp. 734-739, 2006.

[6] V. D. Lima, L. Lourenço, B. Yip, R. S. Hogg, P. Phillips, and J. S. G. Montaner, "AIDS incidence and AIDS-related mortality in British Columbia, Canada, between 1981 and 2013: a retrospective study," The Lancet HIV, vol. 2, no. 3, pp. 92-97, 2015.

[7] M. Farahani, A. Vable, R. Lebelonyane et al., "Outcomes of the Botswana national HIV/AIDS treatment programme from 2002 to 2010: a longitudinal analysis," The Lancet Global Health, vol. 2, no. 1, pp. e44-e50, 2014.

[8] NACP, National guideline for the management of HIV and AIDS, NACP. The United Republic of Tanzania, Ministry of Health and Social Welfare, Dar es Salaam, Tanzania, 4th edition, 2012.

[9] NACP, National guideline for the management of HIV and AIDS, NACP. The United Republic of Tanzania, Ministry of Health and Social Welfare, Dar es Salaam, Tanzania, 5th edition, 2015.

[10] K. A. Van Galen, J. F. Nellen, and P. T. Nieuwkerk, "The effect on treatment adherence of administering drugs as fixed-dose combinations versus as separate pills: systematic review and meta-analysis," AIDS Research and Treatment, vol. 2014, Article ID 967073, pp. 1-6, 2014.

[11] A. Buscher, C. Hartman, M. A. Kallen, and T. P. Giordano, "Impact of antiretroviral dosing frequency and pill burden on adherence among newly diagnosed, antiretroviral-naïve HIV patients," International Journal of STD and AIDS, vol. 23, no. 5, pp. 351-355, 2012.
[12] S. M. Hammer, J. J. Eron Jr., P. Reiss et al., "Antiretroviral treatment of adult HIV infection: 2008 recommendations of the international AIDS society-USA panel," Journal of the American Medical Association, vol. 300, no. 5, pp. 555-570, 2008.

[13] A. J. White, "Mitochondrial toxicity and HIV therapy," Sexually Transmitted Infections, vol. 77, no. 3, pp. 158-173, 2001.

[14] M. J. Feinstein, M. Bogorodskaya, G. S. Bloomfield et al., "Cardiovascular complications of HIV in endemic countries," Current Cardiology Reports, vol. 18, no. 11, article 113, 2016.

[15] S. Subramanian, A. Tawakol, T. H. Burdo et al., "Arterial inflammation in patients with HIV," Journal of the American Medical Association, vol. 308, no. 4, pp. 379-386, 2012.

[16] A. Carr, S. Emery, M. Law et al., "An objective case definition of lipodystrophy in HIV-infected adults: a case-control study," The Lancet, vol. 361, no. 9359, pp. 726-735, 2003.

[17] A. Carr, J. Miller, M. Law, and D. A. Cooper, "A syndrome of lipoatrophy, lactic acidaemia and liver dysfunction associated with HIV nucleoside analogue therapy: contribution to protease inhibitor-related lipodystrophy syndrome," AIDS, vol. 14, no. 3, pp. F25-F32, 2000.

[18] A. Carr, "HIV protease inhibitor-related lipodystrophy syndrome," Clinical Infectious Diseases, vol. 30, no. 2, pp. S135-S142, 2000.

[19] G. A. McComsey, D. M. Paulsen, J. T. Lonergan et al., "Improvements in lipoatrophy, mitochondrial DNA levels and fat apoptosis after replacing stavudine with abacavir or zidovudine," AIDS, vol. 19, no. 1, pp. 15-23, 2005.

[20] A. Carr, K. Samaras, A. Thorisdottir, G. R. Kaufmann, D. J. Chisholm, and D. A. Cooper, "Diagnosis, prediction, and natural course of HIV-1 protease-inhibitor-associated lipodystrophy, hyperlipidaemia, and diabetes mellitus: a cohort study," The Lancet, vol. 353, no. 9170, pp. 2093-2099, 1999.

[21] D. Chen, A. Misra, and A. Garg, "Lipodystrophy in human immunodeficiency virus-infected patients," Journal of Clinical Endocrinology and Metabolism, vol. 87, no. 11, pp. 4845-4856, 2002.

[22] J. Blanch, A. Rousaud, E. Martínez et al., "Impact of lipodystrophy on the quality of life of HIV-1-infected patients," Journal of Acquired Immune Deficiency Syndromes, vol. 31, no. 4, pp. 404407, 2002.

[23] C. C. Schag, R. L. Heinrich, and P. A. Ganz, "Karnofsky performance status revisited: reliability, validity, and guidelines," Journal of Clinical Oncology, vol. 2, no. 3, pp. 187-193, 1984.

[24] WHO, "Obesity: preventing and managing the global epidemic. Report of a WHO consultation," World Health Organization Technical Report Series 894:i-xii, World Health Organization, 2000.

[25] K. A. Lichtenstein, D. J. Ward, A. C. Moorman et al., "Clinical assessment of HIV-associated lipodystrophy in an ambulatory population," AIDS, vol. 15, no. 11, pp. 1389-1398, 2001.

[26] J. Miller, A. Carr, S. Emery et al., "HIV lipodystrophy: prevalence, severity and correlates of risk in Australia," HIV Medicine, vol. 4, no. 3, pp. 293-301, 2003.

[27] M. Ortu, P. Bonfanti, E. Gabrielli, L. Carenzi, R. Gulizia, G. Ferraioli et al., "Ultrasound and lipoatrophy diagnosis: experience on 295 HIV-positive outpatients in antiretroviral therapy," Infection, vol. 37, p. 26, 2009.

[28] P. Filippini, C. Scolastico, M. Battaglia et al., "Lipodystrophy and serum lipid abnormalities in HIV-positive sub-Saharan population on ART," Journal of Infection, vol. 53, no. 1, pp. e29e33, 2006. 
[29] J. van Griensven, R. Zachariah, J. Mugabo, and T. Reid, "Weight loss after the first year of stavudine-containing antiretroviral therapy and its association with lipoatrophy, virological failure, adherence and CD4 counts at primary health care level in Kigali, Rwanda," Transactions of the Royal Society of Tropical Medicine and Hygiene, vol. 104, no. 12, pp. 751-757, 2010.

[30] S. Mercier, N. F. N. Gueye, A. Cournil et al., "Lipodystrophy and metabolic disorders in HIV-1-infected adults on 4- to 9-year antiretroviral therapy in senegal: a case-control study," Journal of Acquired Immune Deficiency Syndromes, vol. 51, no. 2, pp. 224-230, 2009.

[31] M. Galli, F. Veglia, G. Angarano et al., "Gender differences in antiretroviral drug-related adipose tissue alterations: women are at higher risk than men and develop particular lipodystrophy patterns," Journal of Acquired Immune Deficiency Syndromes, vol. 34, no. 1, pp. 58-61, 2003.

[32] N. Andany, J. M. Raboud, S. Walmsley et al., "Ethnicity and gender differences in lipodystrophy of HIV-positive individuals taking antiretroviral therapy in Ontario, Canada," HIV Clinical Trials, vol. 12, no. 2, pp. 89-103, 2011.

[33] E. Sobngwi, J.-C. N. Mbanya, N. C. Unwin et al., "Physical activity and its relationship with obesity, hypertension and diabetes in urban and rural Cameroon," International Journal of Obesity, vol. 26, no. 7, pp. 1009-1016, 2002.

[34] P. Bovet, A. G. Ross, J.-P. Gervasoni et al., "Distribution of blood pressure, body mass index and smoking habits in the urban population of Dar es Salaam, Tanzania, and associations with socioeconomic status," International Journal of Epidemiology, vol. 31, no. 1, pp. 240-247, 2002.

[35] P. W. G. Mallon, J. Miller, D. A. Cooper, and A. Carr, "Prospective evaluation of the effects of antiretroviral therapy on body composition in HIV-1-infected men starting therapy," AIDS, vol. 17, no. 7, pp. 971-979, 2003.

[36] S. Grinspoon and A. Carr, "Cardiovascular risk and body-fat abnormalities in HIV-infected adults," The New England Journal of Medicine, vol. 352, no. 1, pp. 48-62, 2005.

[37] V. Joly, P. Flandre, V. Meiffredy et al., "Increased risk of lipoatrophy under stavudine in HIV-1-infected patients: Results of a substudy from a comparative trial," AIDS, vol. 16, no. 18, pp. 2447-2454, 2002.

[38] G. J. Moyle, C. A. Sabin, J. Cartledge et al., "A randomized comparative trial of tenofovir DF or abacavir as replacement for a thymidine analogue in persons with lipoatrophy," AIDS, vol. 20, no. 16, pp. 2043-2050, 2006.

[39] H. M. Crane, C. Grunfeld, R. D. Harrington, K. K. Uldall, P. S. Ciechanowski, and M. M. Kitahata, "Lipoatrophy among HIVinfected patients is associated with higher levels of depression than lipohypertrophy," HIV Medicine, vol. 9, no. 9, pp. 780-786, 2008.

[40] E. Collins, C. Wagner, and S. Walmsley, "Psychosocial impact of the Lipodystrophy syndrome in HIV infection," AIDS Reader, vol. 10, no. 9, pp. 546-550, 2000.

[41] R. Power, H. L. Tate, S. M. McGill, and C. Taylor, "A qualitative study of the psychosocial implications of lipodystrophy syndrome on HIV positive individuals," Sexually Transmitted Infections, vol. 79, no. 2, pp. 137-141, 2003.

[42] J. Steel, D. Landsittel, B. Calhoun, S. Wieand, and L. A. Kingsley, "Effects of lipodystrophy on quality of life and depression in HIV-infected men on HAART," AIDS Patient Care and STDs, vol. 20 , no. 8 , pp. 565-575, 2006.

[43] E. Hurley, A. Coutsoudis, J. Giddy, S. E. Knight, E. Loots, and T. M. Esterhuizen, "Weight evolution and perceptions of adults living with HIV following initiation of antiretroviral therapy in a South African urban setting," South African Medical Journal, vol. 101, no. 9, pp. 645-650, 2011.

[44] N. I. Paton, A. Earnest, Y. M. Ng, F. Karim, and J. Aboulhab, "Lipodystrophy in a cohort of human immunodeficiency virusinfected asian patients: prevalence, associated factors, and psychological impact," Clinical Infectious Diseases, vol. 35, no. 10, pp. 1244-1249, 2002.

[45] M. Tungsiripat, M. A. O'Riordan, N. Storer et al., "Subjective clinical lipoatrophy assessment correlates with DEXAmeasured limb fat," HIV Clinical Trials, vol. 10, no. 5, pp. 314319, 2009. 


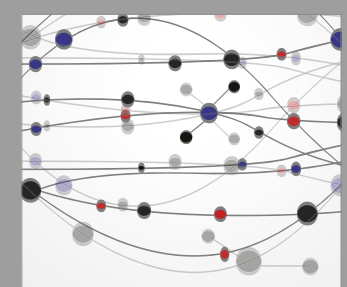

The Scientific World Journal
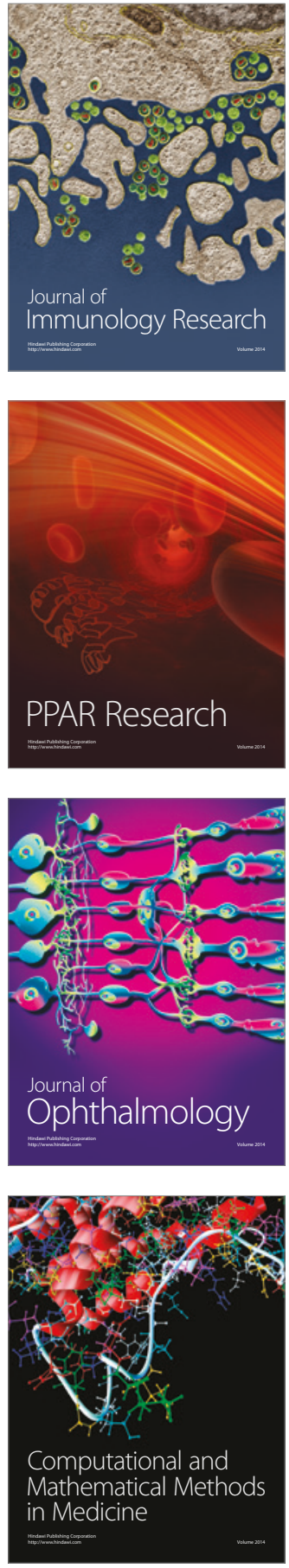

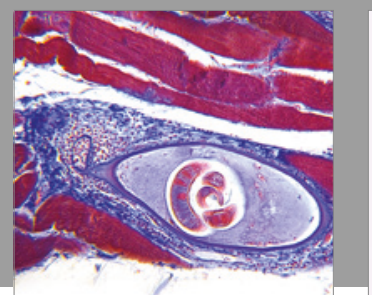

Gastroenterology Research and Practice
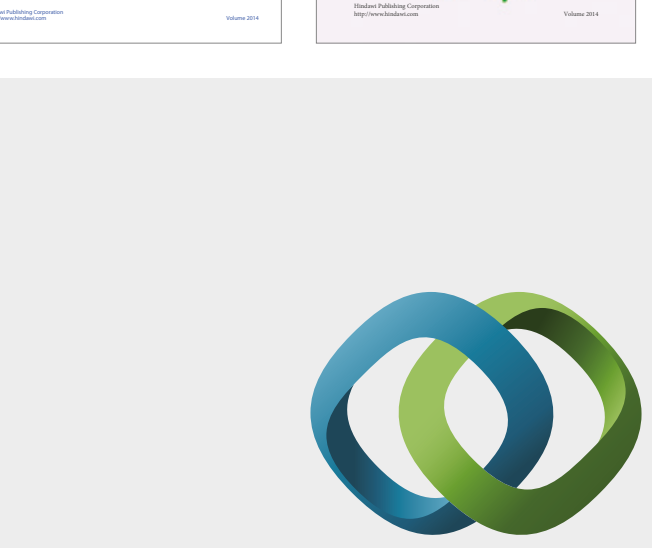

\section{Hindawi}

Submit your manuscripts at

https://www.hindawi.com
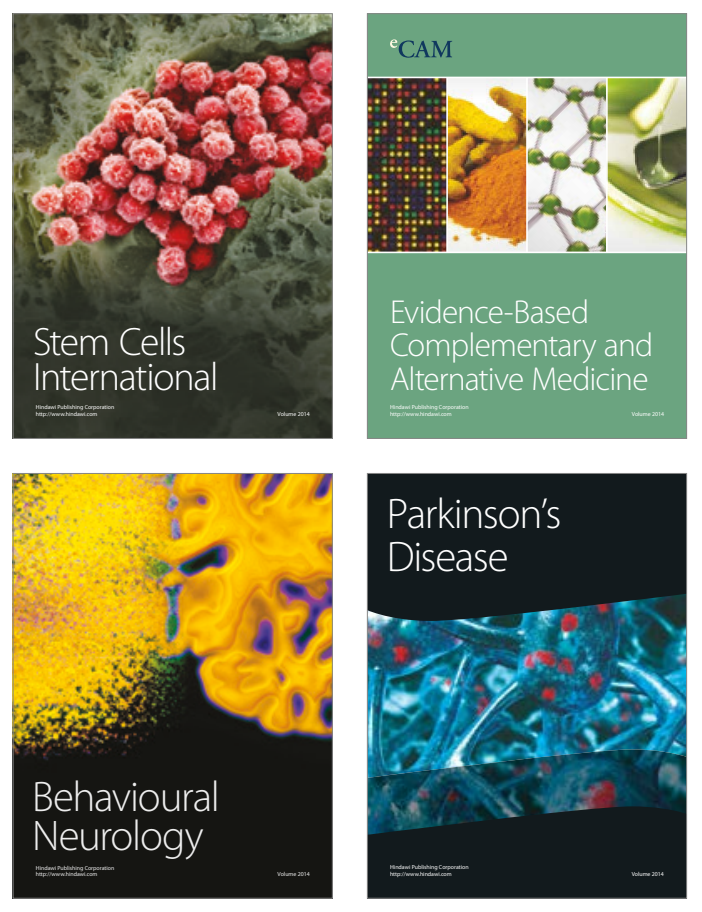
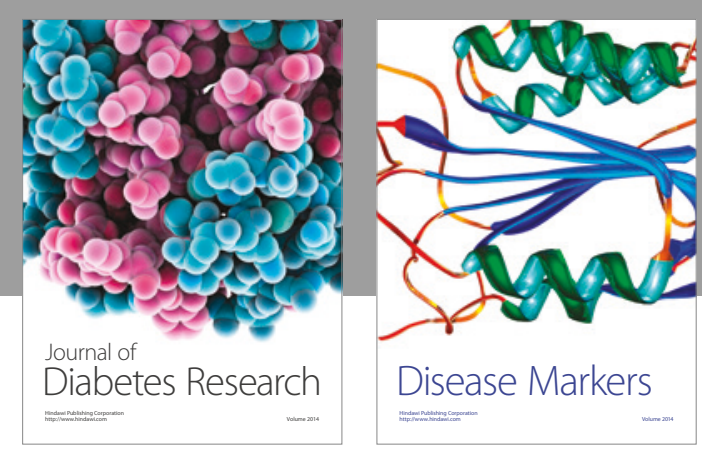

Disease Markers
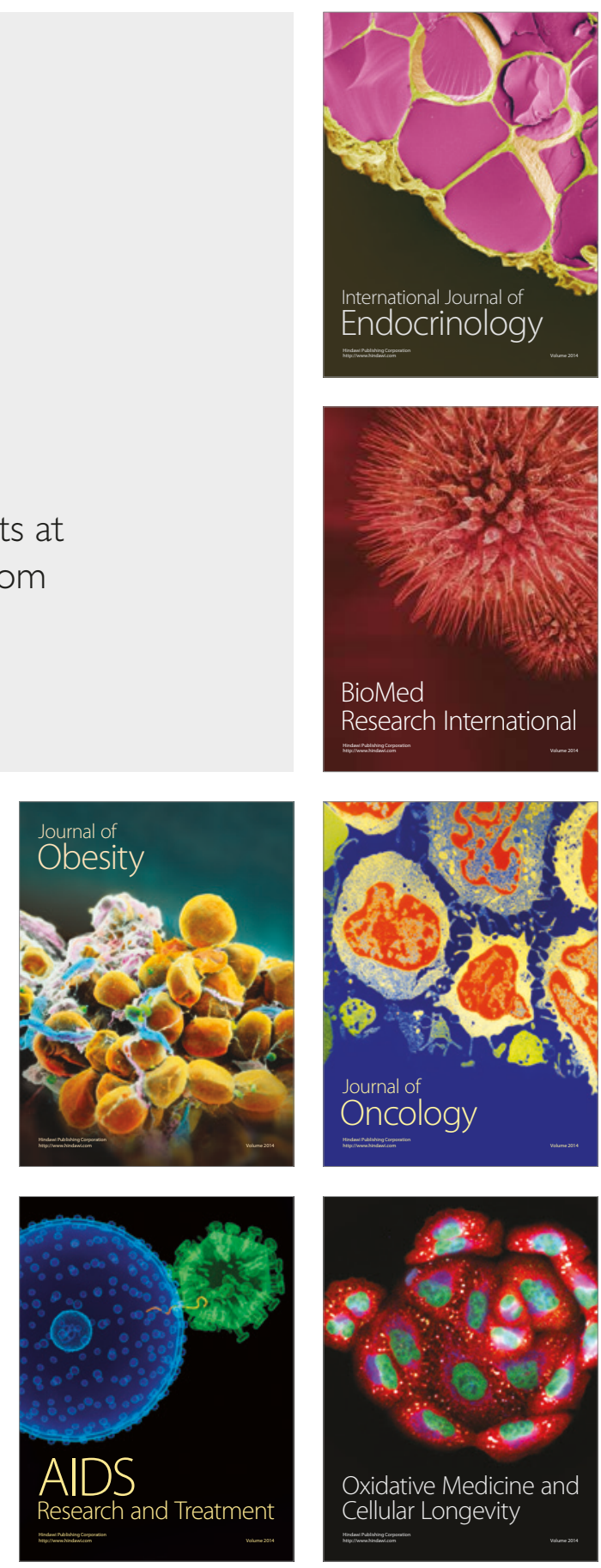